Чуклина Э.Ю.

\title{
ПРАГМАТИЧНАЯ УГОЛОВНАЯ ПОЛИТИКА: НОРМЫ С ДВОЙНОЙ ПРЕВЕНЦИЕЙ В СИСТЕМЕ МЕР СИТУАЦИОННОГО ПРЕДУПРЕЖДЕНИЯ ПРЕСТУПЛЕНИЙ
}

Аннотация: Предметом исследования в статье является криминологическая обоснованность недавно внесенных в Особенную часть Уголовного кодекса РФ дополнений. Анализу подлежат нормы, выраженные в ч. 2 и ч. $3 \mathrm{~cm}$. 171.1, ч. 3 и ч. 4 cm. 327.1, cm. 325.1 и ст. 217.2 УК РФ. Дальнейшее изучение указанных норм посвящено выявлению особенностей криминализаџии запрещенных ими деяний. Внимание акцентируется на криминологической теоретической базе, на которой выстроены новые уголовно-правовые запреты. Метод аналитического исследования установил, что данные нормы выступают в качестве норм с двойной превенцией. Сравнительно-сопоставительный подход позволил предположить, что выявленные закономерности криминализации соответствуют основным положениям концепиии ситуационного предупреждения преступлений. Суть данной концепиии заключается 8 воздействии на преступную мотивацию. Она рекомендована Генеральной Ассамблеей Организации Объединенных Наций в качестве основной стратегии предупреждения преступных посягательств. В статье раскрываются особенности превентивного механизма каждой из рассматриваемых норм, направленных на уменьшение возможностей совершения преступлений. В итоге, исследование показывает, что главной отличительной чертой изучаемых уголовно-правовых норм, является их прагматическая миссия в сфере предупреждения преступлений. Abstract: The object of studies in this article involves criminological substantiation of the recent amendments into the Special Part of the Criminal Code of the Russian Federation. The analysis involved norms of part. 2, 3 of Art. 171.1, part 3,4 of Art. 327.1, Art. 325.1, Art. 217.2 of the Criminal Code of the Russian Federation. The further study of the said norms is devoted to uncovering the specific features of criminalization of acts prohibited by them. Attention is paid to the criminological theoretical basis of the new criminal law prohibitions. The method of analytical study allowed to establish that these norms are double prevention norms. Comparative approach allowed to suppose that these criminalization patterns correspond to the main provisions of the concept of situational crime prevention. The main idea of this concept is influencing the criminal motivation. It is recommended by the General Assembly of the United Nations Organization as the main strategy for the prevention of criminal encroachments. The article discusses specific features of preventive mechanism for each of the norms, which are aimed at lowering the amount of possibility for committing crimes. As a result the study shows that the main specific feature of these criminal law norms is their pragmatic mission in the sphere of crime prevention.

Ключевые слова: Уголовная политика, двойная превенция, Уголовный кодекс, ситуационное предупреждение преступлений, рациональное поведение, преступная мотивация, угроза наказанием, повышенный риск, материальная заинтересованность, прагматичная миссия.

Keywords: Criminal policy, double prevention, Criminal Code of the Russian Federation, situational prevention of crime, rational behavior, criminal motivation, threat of punishment, higher risk, material interest, pragmatic mission.

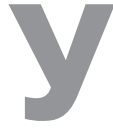

головную политику принято рассматривать как направление деятельности государства в сфере противодействия преступности, в рамках которого определяются стратегия (меры противодействия) и тактика (способы реализации мер противодействия) такой борьбы. Как отмечает В. П. Ревин, для современной уголовной политики характерны, во-первых, возрастание роли специальной профилактики, которая воздействует на определенные виды преступности (организованная, профессиональная, рецидивная и другие), а, во-вторых, приоритет уголовно-правового реагирования на криминальное поведение.'

\footnotetext{
${ }^{1}$ Ревин В. П. О разработке концепции уголовной политики Российской Федерации и совершенствовании законодательства // Пробелы в российском законодательстве. Юридический журнал. - 2008. - № 1. - С. 263
} 
DOI: $10.7256 / 1811-9018.2014 .8 .12555$

При цитировании этой статьи сноска на доі обязательна

\section{Право и политика $8(176) \cdot 2014$}

Одним из основных инструментов уголовной политики является криминализация. Значимость данного процесса и его последствий вызывает острую потребность в криминологической поддержке решений законодателя об установлении нового уголовно-правового запрета. Сказанное надлежит понимать как необходимость оценки норм закона о введении дополнений в УК РФ с точки зрения их соответствия результатам криминологических исследований, посвященных детерминации криминальной активности, личности преступника, а также мерам предупреждения преступных посягательств.

Проблема изучения криминологической обоснованности объявления преступными отдельных деяний приобретает особую актуальность в связи с интенсификацией в 2013-2014 гг. законодательной деятельности, выразившейся в пополнении УК РФ новыми составами преступлений. В частности, выделена уголовная ответственность за производство, приобретение, хранение, перевозку в целях сбыта и продажу подлежащей обязательной маркировке немаркированной алкогольной продукции, совершенные в крупном, особо крупном размере или организованной группой (ч. 2 и ч. 3 ст. $171^{1}$ УК РФ). Помимо этого, предусмотрено наказание за изготовление в целях сбыта или сбыт поддельных акцизных марок либо федеральных специальных марок для маркировки алкогольной продукции и их использование (ч. 3 и ч. 4 ст. $327^{1}$ УК РФ). В рамках главы 24 «Преступления против общественной безопасности» введено уголовное наказание за дачу заведомо ложного экспертного заключения в области промышленной безопасности (ст. $217^{2}$ УК РФ). С августа текущего года уголовному преследованию подлежит неправомерное завладение государственным регистрационным знаком транспортного средства (ст. $325^{1}$ УК РФ).

Вместе с тем ряд представителей научного криминологического сообщества смотрят весьма критично на активизировавшийся процесс криминализации. Так, Д. А. Шестаков видит в излишней криминализации деяний исключительно негативную сторону и приводит ряд доводов, нивелирующих полезность данного института, среди которых указывает низкую эффективность уголовных наказаний, провокацию к нарушению «запретного сладкого плода», загруженность правоохранительных органов. ${ }^{2}$

Я. И. Гилинский полагает, что многие преступные деяния, не причиняющие значительного вреда обще-

\footnotetext{
${ }^{2}$ Шестаков Д. А. Криминология: Новые подходы к преступлению и преступности. Криминогенные законы и криминологическое законодательство. Противодействие преступности в изменяющемся мире: Учебник. СПб.: Юридический Центр Пресс, 2006. С. 309
}

ству и государству (в отличие от таких преступных актов, как убийство, разбой, изнасилование и прочие «типичные» преступления) не заслуживают уголовного преследования и наказания. ${ }^{3}$

По мнению В. В. Лунеева, включение в действующий УК РФ новых положений осуществляется в ситуации отрыва законодательных решений от криминальной действительности, что с неизбежностью обусловливает несвоевременность криминализации определенных деяний. ${ }^{4}$

Действительно, следует отметить, что перечисленные выше составы преступлений и ряд других криминализированных за последнее время деяний, за исключением преступлений террористической направленности, не обладают большой общественной опасностью и снабжены достаточно мягкими санкциями. Однако это не стоит расценивать как поспешный и ничем не подкрепленный акт произвола со стороны законодателя. Напротив, здесь усматривается законодательная логика, претерпевшая существенные изменения по сравнению с традиционной парадигмой конструирования новых уголовно-правовых норм, что требует научного осмысления и обоснования.

Отличительная черта этого подхода состоит в том, что криминализация фокусируется на деяниях, не способных причинить существенный вред сами по себе, однако выступающих предварительным этапом другой более опасной преступной деятельности. Поэтому введение уголовно-правового запрета деяний, совершение которых необходимо для реализации иных преступных посягательств, преследует цель осуществления базовой задачи уголовного законодательства, а именно предупреждения преступлений.

Можно утверждать, что в данном случае речь идет о нормах с двойной превенцией, традиционно относимых к числу эффективных способов воплощения предупредительного потенциала УК РФ. Под ними понимаются нормы, устанавливающие уголовную ответственность за общественно опасные деяния, которые обусловливают совершение других, как правило, более тяжких преступлений. ${ }^{5}$

\footnotetext{
${ }^{3}$ Гилинский Я. И. Криминология. Курс лекций. СПб.: Питер, 2002. C. 310

${ }^{4}$ Лунеев В. В. Курс мировой и российской криминологии: учебник. В 2 т. Т І. Общая часть. М., 2011. С. 846

${ }^{5}$ См.: Саркисова Э.А. Предупредительная роль уголовного закона. Мн., 1979. С. 47. Кузнеиова Н. Ф., Тяжккова И. М. (ред.) Курс уголовного права. Том І. Общая часть. Учение о преступлении. М., 2002. С. 29. Потоикий Н. К. Значение норм уголовного и уголовно-исполнительного права как инструментов обеспечения
} 
Избранная тактика полностью отвечает основным положениям концепции ситуационного предупреждения преступлений, разработанным в стенах Британского государственного отдела криминологических исследований МВД во второй четверти $\mathrm{XX}$ в. Суть ситуационной превенции состоит в уменьшении возможностей для осуществления преступного деяния посредством создания контрусловий, снижающих мотивацию и затрудняющих совершение преступления. ${ }^{6}$ Эффективность применения, относительная простота внедрения и эксплуатации ситуационных превентивных мер, подтверждаемые различными специальными исследованиями, были приняты во внимание Организацией Объединенных Наций, включившей их в «Руководство по основным направлениям предупреждения преступлений» 1990 г. (далее - Руководство).

Согласно данному Руководству система мер ситуационного предупреждения делится на две группы: меры безопасности, которые затрудняют совершение преступления, и меры, снижающие заинтересованность в совершении преступления. Первая группа мер реализуется посредством техник, направленных на укрепление объекта посягательства и усложнения доступа к средствам совершения преступления. Снижение мотивации достигается уменьшением выгодности от совершения преступления и увеличением угрозы разоблачения в совершении уголовно-наказуемого деяния.

При этом указанные меры осуществляются различными способами технического, организационного, психолого-педагогического и правового характера. К последним следует отнести уголовно-правовые нормы с двойной превенцией, запрещающие деяния, которые способствуют криминальной деятельности или интенсифицируют преступную мотивацию.

предупреждения преступлений // Законы России: опыт, анализ, практика. - 2006. - № 5. - С. 114. Ображсиев К.В. Уголовноправовые нормы с двойной превенцией // Проблемы укрепления законности и правопорядка: наука, практика, тенденции. - 2010. № 3. - С. 170-171. Колосова В.И. Специальные нормы уголовного законодательства в борьбе с экономическими и смежными с ними преступлениями (применение норм с «двойной превенцией» и поощрительных норм) // Вестник Нижегородского университета им. Н.И. Лобачевского. - 2012. - № 2 (1). - С. 294

${ }^{6}$ Clarke R. Situational Crime Prevention: Successful Case Studies. New York. 1997. P. 4

${ }^{7}$ Руководство по основным направлениям предупреждения преступлений, которые были подготовлены для представления Восьмому Конгрессу ООН по предупреждению преступности и обращению с правонарушителями (Гавана, Куба, 27 августа - 7 сентября 1990 г.) // Советская юстиция. 1993. № 2. С. 28 - 31; Советская юстиция. 1993 № 3. С. 24 - 27; Советская юстиция. 1993. № 5. С. 25 - 28.
Так, внесение дополнений в ст. $171^{1}$ УК и ст. $327^{1}$ РФ стало последовательным шагом в активизировавшейся работе по усилению государственного регулирования и контроля в данной сфере потребительского рынка.

Действующее законодательство предъявляет достаточно жесткие требования к производителям и продавцам алкогольной продукции в целях защиты здоровья населения от некачественного товара и охраны экономических интересов государства. В частности, согласно ст. 2 Федерального закона от 22.11.1995 № 171Ф3 «О государственном регулировании производства и оборота этилового спирта, алкогольной и спиртосодержащей продукции и об ограничении потребления (распития) алкогольной продукции» вся алкогольная продукция, за исключением некоторых ее видов, подлежит обязательной маркировке федеральными специальными марками или акцизными марками. ${ }^{8}$

Важно заметить, что маркировка имущества представляет собой один из способов ситуационной превенции преступлений, направленный на уменьшение заинтересованности преступника. Будучи средством идентификации объектов, маркировка существенным образом влияет на оборот маркированного имущества, в том числе усложняет его продажу неправомочным лицом. Поэтому снижение мотивации злоумышленника обеспечивается возросшим по сравнению с ожидаемой выгодой риском быть уличенным в преступной деятельности. ${ }^{9}$

Следовательно, законодательно предусмотренная маркировка алкогольной продукции уже является превентивным инструментом на алкогольном рынке. Исходя из положения п. 3 ст. 12 вышеуказанного закона нанесение федеральных специальных марок и акцизных марок выполняет три функции: идентифицирующую, удостоверяющую и фискальную. Во-первых, марки несут в себе информацию о наименовании, виде алкогольной продукции, производителе, соответствии ее установленным требованиям качества и безопасности и др., которая фиксируется в информационной системе учета производства и оборота алкогольной продукции. Во-вторых, наличие маркировки подтверждает законность предпринимательской деятельности по

\footnotetext{
${ }^{8}$ Федеральный закон от 22.11.1995 № 171-Ф3 «О государственном регулировании производства и оборота этилового спирта, алкогольной и спиртосодержащей продукции и об ограничении потребления (распития) алкогольной продукции» // Российская газета, 29.11.1995, № 231 .

${ }^{9}$ Clarke R. Situational Crime Prevention: Successful Case Studies. New York. 1997. Р. 22; Руководство по основным направлениям предупреждения преступлений // Советская юстиция. 1993. № 5. C. $25-28$.
} 


\section{Право и политика $8(176) \cdot 2014$}

производству или обороту алкогольной продукции, т.е. наличие лицензии, сертификатов соответствия, технологической оснащенности и т.д. Наконец, она служит целям контроля за уплатой налогов, поскольку налоговые ставки исчисляются исходя из сведений об алкогольной продукции, содержащихся на федеральных специальных или акцизных марках.

Содержание перечисленных функций свидетельствует о том, что маркировка призвана, с одной стороны, воспрепятствовать незаконному предпринимательству и извлечению незаконных и неконтролируемых доходов в сфере производства или оборота алкогольной продукции (ст. ст. 171, 199, $199^{2}$ УК РФ), а с другой - не допустить нарушение требований к качеству алкогольной продукции и причинение вреда здоровью потребителей (ст. ст. 236, 238 УК РФ).

Однако статистика правонарушений, выявленных Федеральной службой по регулированию алкогольного рынка (280 407 нарушений за 2010-2012) ${ }^{10}$, демонстрирует недостаточную эффективность маркировки как предупредительного средства. Связано это с тем, что недобросовестные предприниматели изыскивают способы, которые позволяют миновать обеспечиваемый маркировкой государственный контроль в сфере алкогольного рынка. Основными обходными путями, которыми могут воспользоваться злоумышленники, являются неисполнение обязанности по маркировке алкогольной продукции или использование поддельных федеральных специальных и акцизных марок. Поэтому введение в УК РФ ч. 3 и 4 ст. $171^{1}$ и ч. 3 и 4 ст. $327^{1}$ УК РФ следует рассматривать в качестве меры, устраняющей возможности избежать последствий функционирования маркировки.

Предполагается, что угроза привлечения к уголовной ответственности побудит потенциальных преступников либо отказаться от бизнеса в сфере алкогольного товарооборота, либо следовать законодательно установленным требованиям к маркировке алкогольной продукции. А непосредственно применение уголовного наказания в соответствии с данными нормами УК РФ, в особенности на ранних стадиях незаконной деятельности (производство алкогольной продукции, ее перевозка и хранение, изготовление поддельных марок), обеспечит пресечение преступлений, предусмотренных ст. ст. 171, 199, 199², 236 и 238 УК РФ.

Классическим примером ситуационного предупреждения преступлений посредством маркировки

\footnotetext{
${ }^{10}$ Основные показатели, характеризующие рынок алкогольной продукции в 2010 - 2012 гг. // Статистический сборник Федеральной службы по регулированию алкогольного рынка. М., 2013.
}

служит нанесение идентификационных номеров на транспортные средства (Vehicle Identification Numbers, VINs). ${ }^{11}$ В сфере борьбы с криминальным рынком автомобилей, а также преступлениями, совершаемыми с использованием транспортных средств, превентивный эффект транспортной маркировки усиливают автоматизированные системы учета, контроля за оборотом и розыска транспортных средств.

Вместе с тем государственный регистрационный знак, изготавливаемый в соответствии с требованиями государственного стандарта и выдаваемый специально уполномоченными органами ${ }^{12}$, является одним из наиболее доступных для злоумышленников транспортных идентификационных параметров. В преступных руках он становится инструментом придания видимой легальности незаконному сбыту автомобилей, а равно усложнения оперативно-розыскных и следственных мероприятий по установлению лиц, причастных к преступлениям с использованием транспортных средств.

В этой связи законодатель счел необходимым снабдить государственный регистрационный знак правовой защитой в виде административного наказания за неправомерное завладение данным элементом транспортной маркировки и уголовной ответственности, если указанное деяние обусловлено корыстной заинтересованностью либо целью совершения тяжкого или особо тяжкого преступления.

Как и в случае с уголовно-правовыми нормами о маркировке алкогольной продукции, положения ст. $325^{1}$ УК РФ содержат сигнал о повышенном риске подвергнуться уголовному наказанию за подготовительные действия к дальнейшей преступной деятельности, что должно вынудить злоумышленника отказаться от реализации намеченного плана. В свою очередь, привлечение к ответственности за совершение рассматриваемого деяния работает на пресечение преступлений, связанных с криминальным сбытом автомобилей (ст. ст. 158, 174, 174니 175, 325, 326, 327 УК РФ), и иных преступлений, для совершения которых могут использоваться транспортные средства (например, ст. ст. 126, 222, 228 УК РФ и др.).

\footnotetext{
${ }^{11}$ Clarke R. Situational Crime Prevention: Successful Case Studies. New York. 1997. P. 22; Cornish D., Clarke R. Opportunities, Precipitators and Criminal Decisions: a Replay to Wortley's Critique of Situational Crime Prevention // Crime Prevention Studies, vol. 16 (2003). Рp. 41 - 93. Руководство по основным направлениям предупреждения преступлений // Советская юстиция. 1993. № 5. С. 25 - 28

${ }^{12}$ Архипов А.А., Шарапов Р.Д. Уголовная ответственность за преступления, связанные с фальсификацией номерных регистрационно-учетных параметров транспортных средств: монография. - М.: Юрлитинформ, 2012. С. 41
} 
Концепция ситуационного предупреждения преступных посягательств фокусирует внимание на рациональности поведения потенциального преступника. Поэтому большинство ситуативных техник направлено на блокировку путей извлечения доходов от преступной деятельности и увеличение угрозы разоблачения в замышляемом уголовно-наказуемом деянии.

Введение в УК РФ ст. $217^{2}$ продиктовано стремлением минимизировать возможность профессиональных экспертов извлекать прибыль из предоставления ложных заключений, которые позволяют возводить и эксплуатировать опасные производственные объекты с нарушением установленных правил безопасности.

В соответствии с действующим законодательством эксперт обязан на основании анализа письменных материалов и фактического состояния технических устройств, зданий и сооружений сформулировать обоснованное и объективное заключение о степени защищенности исследуемого объекта от аварий и других внешних или внутренних негативных воздействий. Экспертиза должна осуществляться на этапах ввода в эксплуатацию опасного производственного объекта, проведения его капитального ремонта, реконструкции и ликвидации. ${ }^{13}$ Уголовно-правовой запрет на дачу заведомо ложного заключения в сфере промышленной безопасности имеет два взаимосвязанных превентивных последствия. Во-первых, решимость экспертов преступить закон существенно снизится от осознания того, что материальная выгода может обернуться судимостью. Вовторых, усиление ответственности экспертов в сфере промышленной безопасности вызовет значительный рост цен на оказываемые ими услуги, что приведет к сокращению спроса на ложные заключения экспертизы промышленной безопасности.

Результатом приведенных тенденций надлежит ожидать предупреждение совершения трех групп преступных посягательств: 1) указанных в диспозиции ст. $217^{2}$ УК РФ уголовно-наказуемых деяний (ст. ст. 109, 118, 168 УК РФ); 2) преступлений, связанных с нарушением различных правил безопасности на опасных производственных объектах (ст. ст. 215, 216, 217 УК РФ); 3) преступлений, влекущих частичное или полное разрушение этих объектов (ст. ст. $215^{2}, 215^{3}, 281$ УК РФ).

Таким образом, в рамках современной политики борьбы с преступностью отчетливо наметилась тен-

\footnotetext{
${ }^{13}$ Федеральный закон от 21.07.1997 № 116-Ф3 «О промышленной безопасности опасных производственных объектов» // Российская газета. 30.07.1997. № 145
}

денция использования уголовного законодательства в качестве предупредительного инструмента, одним из элементов которого выступают нормы с двойной превенцией. Именно в этом заключается прагматичная сущность современной уголовной политики, которая опирается на модернизированный процесс криминализации, способный обеспечить сокращение преступных проявлений.

Избрав тактику воздействия на мотивацию потенциального преступника, а также на его реальную возможность претворить в жизнь криминальные намерения, законодатель демонстрирует научно-обоснованный подход к противодействию преступности. Внедрение концепции ситуационной превенции преступлений в российское поле уголовной политики представляется актуальным и необходимым в условиях усиления профессионализма, организованности и технической и вооруженной оснащенности современного преступного мира.

\section{Библиография:}

1. Clarke R. Situational Crime Prevention: Successful Case Studies. New York. Harrow and Heston Publishers. 1997. - 43 p.;

2. Cornish D., Clarke R. Opportunities, Precipitators and Criminal Decisions: a Replay to Wortley's Critique of Situational Crime Prevention // Crime Prevention Studies, vol. 16 (2003). Pp. 41 - 93;

3. Архипов А.А., Шарапов Р.Д. Уголовная ответственность за преступления, связанные с фальсификацией номерных регистрационно-учетных параметров транспортных средств: монография. - М.: Юрлитинформ, 2012. - 144 с.

4. Гилинский Я. И. Криминология. Курс лекций. СПб.: Питер, 2002. - 384 с.;

5. Колосова В.И. Специальные нормы уголовного законодательства в борьбе с экономическими и смежными с ними преступлениями (применение норм с «двойной превенцией» и поощрительных норм) // Вестник Нижегородского университета им. Н.И. Лобачевского. 2012. № 2 (1). С. 293 - 298;

6. Кузнецова Н. Ф., Тяжкова И. М. (ред.) Курс уголовного права. Том I. Общая часть. Учение о преступлении. М., 2002. - 624 с.;

7. Лунеев В. В. Курс мировой и российской криминологии: учебник. В 2 т. Т І. Общая часть. М.: Издательство Юрайт, 2011. - 1003 с.;

8. Ображиев К.В. Уголовно-правовые нормы с двойной превенцией // Проблемы укрепления законно- 


\section{Право и политика $8(176) \cdot 2014$}

сти и правопорядка: наука, практика, тенденции. 2010. № 3. С. 167-171;

9. Потоцкий Н. К. Значение норм уголовного и уголовно-исполнительного права как инструментов обеспечения предупреждения преступлений // Законы России: опыт, анализ, практика. 2006. № 5. С. 112 - 117;

10. Ревин В. П. О разработке концепции уголовной политики Российской Федерации и совершенствовании законодательства // Пробелы в российском законодательстве. Юридический журнал. 2008. № 1. С. 262 - 264;

11. Саркисова Э.А. Предупредительная роль уголовного закона. Мн.: Наука и Техника, 1979. - 146 с.;

12. Шестаков Д. А. Криминология: Новые подходы к преступлению и преступности. Криминогенные законы и криминологическое законодательство. Противодействие преступности в изменяющемся мире: Учебник. СПб.: Юридический Центр Пресс, 2006. - 561 c.

13. Силаева Н.А. Нормативно-правовое обеспечение предупреждения преступлений, посягающих на политическую систему Российской Федерации // NB: Национальная безопасность. - 2013. - 2. - С. 88111. DOI: 10.7256/2306-0417.2013.2.692. URL: http://www.e-notabene.ru/nb/article_692.html

14. Антохина А.Б. Меры безопасности в романо-германской (континентальной) правовой системе // Право и политика. - 2014. - 4. - C. 447-451. DOI: 10.7256/1811-9018.2014.4.11620.

15. Айрих В.А. Соотношение общественной безопасности и превенции в полицейском праве ФРГ // NB: Национальная безопасность. - 2013. - № 1. C.254-289. DOI: 10.7256/2306-0417.2013.1.312. URL: http://e-notabene.ru/nb/article_312.html

16. Прокофьев К.Г.. Роль полиции в реализации административной ответственности за нарушение законодательства о собраниях, митингах, демонстрациях, шествиях и пикетировании // Полицейская деятельность. - 2014. - № 2. - C. 104-107. DOI: 10.7256/2222-1964.2014.2.11921

17. Изюмова Е.С.. Административная преюдиция уголовной ответственности за незаконную организацию игорной деятельности. // Административное и муниципальное право. - 2014. - № 4. - С. 104-107. DOI: 10.7256/1999-2807.2014.4.11299

18. Боровков М.С.. Комплекс превентивных мер по защите бизнеса от враждебного поглощения // Национальная безопасность / nota bene. - 2014. - № 1. - C. 104-107. DOI: 10.7256/2073-8560.2014.1.10471
19. Кареева-Попелковская К.А.. Механизм применения мер административного пресечения // Полицейская деятельность. - 2014. - № 1. - С. 104107. DOI: $10.7256 / 2222-1964.2014 .1 .10641$

20. Игонин Д.И.. Определение стратегических приоритетов в государственной миграционной политике России как превентивная мера социальной дезадаптации. // Тренды и управление. - 2013. - № 4. - C. 104-107. DOI: 10.7256/2307-9118.2013.4.4880

21. Н.С. Киселев. Превентивная защита от рейдерских атак // Национальная безопасность / nota bene. - 2013. - № 1. - C. 104-107. DOI: 10.7256/20738560.2013.01.18

22. М.О. Акопджанова. Противодействие уклонению от уплаты транспортного налога // Налоги и налогообложение. - 2012. - № 8. - С. 104-107.

23. В.А. Айрих. Превенция в контексте полицейского права // Национальная безопасность / nota bene. 2012. - № 5. - С. 104-107.

24. Акопджанова М.О.. Криминологическая характеристика налоговой преступности // Налоги и налогообложение. - 2011. - № 10. - С. 104-107.

25. Д. Г. Алексеева. Правовое регулирование мониторинга финансовой устойчивости банков в целях обеспечения банковской безопасности // Политика и Общество. - 2011. - № 6. - С. 104-107.

26. Кобец П.Н.. О предупреждении преступлений - как сложном, многогранном процессе, обладающем определенными признаками целостности // Полицейская деятельность. - 2011. - № 4. С. 104-107

27. Алейников А.В. Системные конфликты в России: концептуальные основания анализа. Статья II. // NB: Проблемы общества и политики. - 2013. - 8. C. 1 - 47. DOI: 10.7256/2306-0158.2013.8.5109. URL: http://www.e-notabene.ru/pr/article_5109.html

28. Алейников А.В. Системные конфликты в России: концептуальные основания анализа. Статья 1. // NB: Проблемы общества и политики. - 2013. - 7. - C. 94 - 140. DOI: 10.7256/2306-0158.2013.7.2306. URL: http://www.e-notabene.ru/pr/article_2306.html

\section{References (transliteration):}

1. Clarke R. Situational Crime Prevention: Successful Case Studies. New York. Harrow and Heston Publishers. 1997. - 43 p.;

2. Cornish D., Clarke R. Opportunities, Precipitators and Criminal Decisions: a Replay to Wortley's Critique 
DOI: $10.7256 / 1811-9018.2014 .8 .12555$

При цитировании этой статьи сноска на doi обязательна

Закон и правопорядок

of Situational Crime Prevention // Crime Prevention Studies, vol. 16 (2003). Pp. 41 - 93;

3. Arkhipov A.A., Sharapov R.D. Ugolovnaya otvetstvennost' za prestupleniya, svyazannye s fal'sifikatsiei nomernykh registratsionno-uchetnykh parametrov transportnykh sredstv: monografiya. - M.: Yurlitinform, 2012. - $144 \mathrm{~s}$.

4. Gilinskii Ya. I. Kriminologiya. Kurs lektsii. SPb.: Piter, 2002. - 384 s.;

5. Kolosova V.I. Spetsial'nye normy ugolovnogo zakonodatel'stva $v$ bor'be s ekonomicheskimi i smezhnymi s nimi prestupleniyami (primenenie norm $\mathrm{s}$ «dvoinoi preventsiei» i pooshchritel'nykh norm) // Vestnik Nizhegorodskogo universiteta im. N.I. Lobachevskogo. 2012. № 2 (1). S. 293 - 298;

6. Kuznetsova N. F., Tyazhkova I. M. (red.) Kurs ugolovnogo prava. Tom I. Obshchaya chast'. Uchenie o prestuplenii. M., 2002. - 624 s.;

7. Luneev V. V. Kurs mirovoi i rossiiskoi kriminologii: uchebnik. V 2 t. T I. Obshchaya chast'. M.: Izdatel'stvo Yurait, 2011. - 1003 s.;

8. Obrazhiev K.V. Ugolovno-pravovye normy s dvoinoi preventsiei // Problemy ukrepleniya zakonnosti i pravoporyadka: nauka, praktika, tendentsii. 2010. № 3 . S. 167-171;

9. Pototskii N. K. Znachenie norm ugolovnogo i ugolovno-ispolnitel'nogo prava kak instrumentov obespecheniya preduprezhdeniya prestuplenii // Zakony Rossii: opyt, analiz, praktika. 2006. № 5. S. 112 - 117;

10. Revin V. P. O razrabotke kontseptsii ugolovnoi politiki Rossiiskoi Federatsii i sovershenstvovanii zakonodatel'stva // Probely v rossiiskom zakonodatel'stve. Yuridicheskii zhurnal. 2008. № 1. S. 262-264;

11. Sarkisova E.A. Predupreditel'naya rol' ugolovnogo zakona. Mn.: Nauka i Tekhnika, 1979. - 146 s.;

12. Shestakov D. A. Kriminologiya: Novye podkhody k prestupleniyu i prestupnosti. Kriminogennye zakony $\mathrm{i}$ kriminologicheskoe zakonodatel'stvo. Protivodeistvie prestupnosti $v$ izmenyayushchemsya mire: Uchebnik. SPb.: Yuridicheskii Tsentr Press, 2006. - 561 s.

13. Silaeva N.A. Normativno-pravovoe obespechenie preduprezhdeniya prestuplenii, posyagayushchikh na politicheskuyu sistemu Rossiiskoi Federatsii // NB: Natsional'naya bezopasnost'. - 2013. - 2. - C. 88-111. DOI: 10.7256/2306-0417.2013.2.692. URL: http:// www.e-notabene.ru/nb/article_692.html

14. Antokhina A.B. Mery bezopasnosti v romano-germanskoi (kontinental'noi) pravovoi sisteme // Pravo i politika. - 2014. - 4. - C. 447-451. DOI: 10.7256/18119018.2014.4.11620.
15. Airikh V.A. Sootnoshenie obshchestvennoi bezopasnosti i preventsii $\mathrm{v}$ politseiskom prave FRG // NB: Natsional'naya bezopasnost'. - 2013. - № 1. - S.254289. DOI: $10.7256 / 2306-0417.2013 .1 .312$. URL: http://enotabene.ru/nb/article_312.html

16. Prokof'ev K.G.. Rol' politsii v realizatsii administrativnoi otvetstvennosti za narushenie zakonodatel'stva o sobraniyakh, mitingakh, demonstratsiyakh, shestviyakh i piketirovanii // Politseiskaya deyatel'nost'. - 2014. - № 2. - S. 104-107. DOI: 10.7256/22221964.2014.2.11921

17. Izyumova E.S.. Administrativnaya preyuditsiya ugolovnoi otvetstvennosti za nezakonnuyu organizatsiyu igornoi deyatel'nosti. // Administrativnoe i munitsipal'noe pravo. - 2014. - № 4. - S. 104-107. DOI: 10.7256/1999-2807.2014.4.11299

18. Borovkov M.S.. Kompleks preventivnykh mer po zashchite biznesa ot vrazhdebnogo pogloshcheniya // Natsional'naya bezopasnost' / nota bene. - 2014. - № 1. - S. 104-107. DOI: 10.7256/20738560.2014.1.10471

19. Kareeva-Popelkovskaya K.A.. Mekhanizm primeneniya mer administrativnogo presecheniya // Politseiskaya deyatel'nost'. - 2014. - № 1. - S. 104-107. DOI: 10.7256/2222-1964.2014.1.10641

20. Igonin D.I.. Opredelenie strategicheskikh prioritetov $\mathrm{v}$ gosudarstvennoi migratsionnoi politike Rossii kak preventivnaya mera sotsial'noi dezadaptatsii. // Trendy i upravlenie. - 2013. - № 4. - S. 104-107. DOI: 10.7256/2307-9118.2013.4.4880

21. N.S. Kiselev. Preventivnaya zashchita ot reiderskikh atak // Natsional'naya bezopasnost' / nota bene. - 2013 . - № 1. - S. 104-107. DOI: 10.7256/2073-8560.2013.01.18

22. M.O. Akopdzhanova. Protivodeistvie ukloneniyu ot uplaty transportnogo naloga // Nalogi i nalogooblozhenie. - 2012. - № 8. - S. 104-107.

23. V.A. Airikh. Preventsiya v kontekste politseiskogo prava // Natsional'naya bezopasnost' / nota bene. 2012. - № 5. - S. 104-107.

24. Akopdzhanova M.O.. Kriminologicheskaya kharakteristika nalogovoi prestupnosti // Nalogi i nalogooblozhenie. - 2011. - № 10. - S. 104-107.

25. D. G. Alekseeva. Pravovoe regulirovanie monitoringa finansovoi ustoichivosti bankov $\mathrm{v}$ tselyakh obespecheniya bankovskoi bezopasnosti // Politika i Obshchestvo. - 2011. - № 6. - S. 104-107.

26. Kobets P.N.. O preduprezhdenii prestuplenii - kak slozhnom, mnogogrannom protsesse, obladayushchem opredelennymi priznakami tselostnosti // Politseiskaya deyatel'nost'. - 2011. - № 4. - S. 104-107 
DOI: $10.7256 / 1811-9018.2014 .8 .12555$

При цитировании этой статьи сноска на dоі обязательна

\section{Право и политика $8(176) \cdot 2014$}

27. Aleinikov A.V. Sistemnye konflikty v Rossii: kontseptual'nye osnovaniya analiza. Stat'ya II. // NB: Problemy obshchestva i politiki. - 2013. - 8. - C. 1 47. DOI: 10.7256/2306-0158.2013.8.5109. URL: http:// www.e-notabene.ru/pr/article_5109.html
28. Aleinikov A.V. Sistemnye konflikty v Rossii: kontseptual'nye osnovaniya analiza. Stat'ya 1. // NB: Problemy obshchestva i politiki. - 2013. - 7. - C. 94 140. DOI: 10.7256/2306-0158.2013.7.2306. URL: http:// www.e-notabene.ru/pr/article_2306.html 